See Article page 1519.

\section{Commentary: Not safe at any flow: The challenges of low-flow pediatric operation of adult continuous-flow ventricular assist devices}

\author{
Ryan R. Davies, MD
}

With the exception of the Berlin Heart EXCOR ventricular assist device (VAD), ${ }^{1}$ no durable VAD has yet been approved by the Food and Drug Administration for use in children. However, over the past 20 years, VADs approved for use in adults have demonstrated marked improvement in clinical outcomes while also being drastically reduced in physical size. ${ }^{2-4}$ These factors, along with a design enabling potential discharge and long-term out-of-hospital support, have led to increasing enthusiasm for the use of these adult VADs in smaller children. ${ }^{5}$ Unfortunately, the consequences of running these adult pumps at lower flows and in smaller ventricular cavities remains uncertain.

The study by Granegger and colleagues in this issue of the Journal demonstrates the pitfalls of assuming that outcomes will be the same in children as in adults. ${ }^{6}$ The authors used a combination of in vivo, in silica, and in vitro studies to examine the effect of the lower flows used in children on blood trauma with the HeartWare HVAD VAD pump. The clinical information from the in vivo studies is of limited value, but it does demonstrate that measures of blood trauma, most notably lactate dehydrogenase, appear to remain elevated for longer periods following VAD implantation in pediatric patients. This is consistent with preliminary data regarding other continuous-flow devices used in children (ACTION network, personal communication). The in silica studies using computational fluid dynamics

\footnotetext{
From the Department of Cardiovascular and Thoracic Surgery, UT Southwestern Medical Center and Children's Health, Dallas, Tex.

Disclosures: Author has nothing to disclose with regard to commercial support.

Received for publication Oct 31, 2019; revisions received Oct 31, 2019; accepted for publication Oct 31, 2019; available ahead of print Jan 29, 2020.

Address for reprints: Ryan R. Davies, MD, Department of Cardiovascular and Thoracic Surgery, UT Southwestern Medical Center and Children's Health, 1935 Medical District Dr, MC B3.410, Dallas, TX 75235 (E-mail: ryan.davies@ utsouthwestern.edu).

J Thorac Cardiovasc Surg 2020;159:1530-1

$0022-5223 / \$ 36.00$

Copyright $(C) 2019$ by The American Association for Thoracic Surgery

https://doi.org/10.1016/j.jtcvs.2019.10.208
}

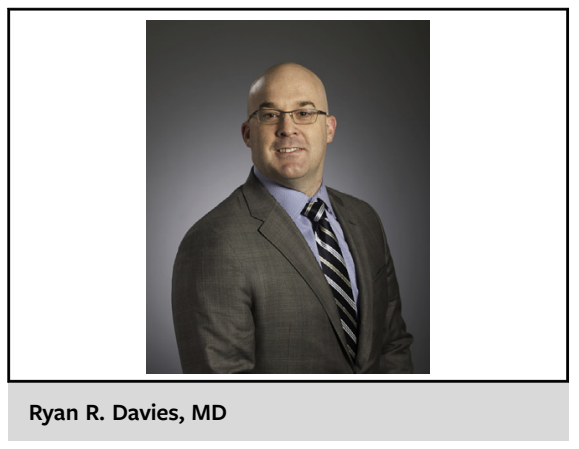

CENTRAL MESSAGE

Outcomes with the use of adult pumps are likely to be different under pediatric operating conditions than under standard adult conditions.

are more compelling regarding the predicted differences in both stasis and shear stress within the pump during pediatric and adult operating conditions. The larger volume of static blood and longer time for blood exchange at lowspeed operation may predispose to thrombus formation and contribute to pump inefficiency and blood trauma. The in vitro studies support an important clinical effect from lower-speed operation with increased measures of hemolysis compared with adult settings.

All these data provide a compelling story that suggests that we should not expect the same clinical behavior and outcomes under low-flow pediatric operation, as has been reported in standard-flow adult operation. This is likely part of the explanation for the trend toward poorer outcomes when the HVAD is used in pediatric patients with body surface area $<1 \mathrm{~m}^{2} .5$ Challenges with pump positioning, the influence of smaller ventricles, and the position of the papillary muscles, as well as the difficulty reaching hospital discharge, ${ }^{5}$ and full rehabilitation may also play a role.

The data in this issue of the Journal demonstrates the importance of careful consideration before simply using an adult pump in small pediatric patients under operating conditions that have not been evaluated. It reinforces the need to continue to evaluate these pumps in children to identify whether changes to anticoagulation regimens and alterations in standard clinical practices derived from adults are necessary to optimize outcomes in pediatric operating conditions. Finally, it suggests that ongoing development of pediatric-specific continuous-flow pumps, including the Jarvik 2015, as well as the PediaFlow pump and others, is 
likely to be critical in realizing similar improvements in the outcomes of VAD use in pediatric patients as have been seen in adults. Children are not simply small adults; just because we can make an adult pump fit into a pediatric patient does not mean that we can expect management and results to mirror those in adults. Continued research into both pediatric-specific pumps and the application of adult pumps to pediatric operating conditions is needed to maximize the quality and length of life obtainable for children requiring mechanical circulatory support.

\section{References}

1. Fraser CD, Jaquiss RDB, Rosenthal DN, Humpl T, Canter CE, Blackstone EH, et al; Berlin Heart Study Investigators. Prospective trial of a pediatric ventricular assist device. N Engl J Med. 2012;367:532-41.
2. Rogers JG, Pagani FD, Tatooles AJ, Bhat G, Slaughter MS, Birks EJ, et al. Intrapericardial left ventricular assist device for advanced heart failure. $N$ Engl J Med. 2017;376:451-60.

3. Mehra MR, Uriel N, Naka Y, Cleveland JC, Yuzefpolskaya M, Salerno CT, et al; MOMENTUM 3 Investigators. A fully magnetically levitated left ventricular assist device: final report. $N$ Engl J Med. 2019; 380:1618-27.

4. Jorde UP, Kushwaha SS, Tatooles AJ, Naka Y, Bhat G, Long JW, et al; HeartMate II Clinical Investigators. Results of the destination therapy post-food and drug administration approval study with a continuous-flow left ventricular assist device: a prospective study using the INTERMACS registry (Interagency Registry for Mechanically Assisted Circulatory Support). J Am Coll Cardiol. 2014; 63:1751-7.

5. Conway J, Miera O, Adachi I, Maeda K, Eghtesady P, Henderson HT, et al Pediatric VAD Investigators. Worldwide experience of a durable centrifugal flow pump in pediatric patients. Semin Thorac Cardiovasc Surg. 2018;30:327-35.

6. Granegger M, Thamsen B, Schlöglhofer T, Lach S, Escher A, Haas T, et al. Blood trauma potential of the HeartWare Ventricular Assist Device in pediatric patients. J Thorac Cardiovasc Surg. 2020;159:1519-27.e1. 